Lords to allow sterilisation of a severely handicapped 36 year old woman to prevent an unwanted pregnancy. This judgement applies to all types of treatment and is based on the common law principle necessity, which allows doctors to treat unconscious patients in casualty. According to the BMJ's legal correspondent (BMJ, 298, 10 June 1989), this extension of common law can now allow for treatment to patients unable to consent, through mental illness or handicap, if the treatment or operation is in their best interests. Such intervention must be "either to save their lives or to ensure improvement or prevent deterioration in their physical or mental health" (Lord Brandon). It seems, therefore, that such treatment need not be only in the nature of emergency treatment.

This ruling has certain implications for psychiatry. Firstly, in the liaison psychiatry, when we are asked by our surgical or medical colleagues whether they can treat patients with mental illness or handicap who are declining treatment, we should advise them that they can do so. For example, the elderly schizophrenic patient with a gangrenous foot can be treated electively rather than waiting until he is unconscious, and the paracetamol self-poisoner can be given intravenous $\mathrm{N}$-acetylcysteine against his will, as long as some doctor has decided that the person is mentally ill. It is unclear in the Law Lords' judgement whether such a decision that someone is mentally ill has to be made by a psychiatrist.

Secondly, this judgement widens the rift between psychiatry and all other branches of medicine in that under the terms of the Mental Health Act 1983, a mentally ill person who needs but refuses treatment for his mental illness cannot be so treated, except in an emergency, until a second opinion has been sought. The position with regard to psychosurgery is still further divorced from the rest of medicine.

Thirdly, from a general ethical viewpoint, it is interesting to note that this judgement represents a substantial victory of paternalism over individual autonomy as the basis of doctors' dealings with their patients.

University of Liverpool

L. M. LOVETT

Royal Liverpool Hospital

Liverpool L69 3BX

\section{Consultant vacancies}

DeAr SIRS

I was interested in the letter from Dr Jolley about unfilled consultant posts (Psychiatric Bulletin, 13, 248-249). You might be interested in the other side of the coin, so to speak.
After 20 years service as a consultant I resigned from the NHS to take up an appointment in Canada. For some months all went well then a combination of circumstances decided me to try and return. This was much easier said than done. I telephoned several locum agencies whose addresses I found in the BMJ. Most said they were concerned only with nonconsultant vacancies; a few promised to send on their registration forms but didn't. I then took the course of submitting my CV to four Regional Health Authorities asking them to put my name on their locum consultant registers. These applications were sent by airmail, in two cases by Special Delivery. Only one authority actually replied.

In view of my experiences I find the letter of Dr Jolley all the more surprising. The only explanations I can offer are either the number of consultant vacancies has diminished considerably in 1989 or the Regional Health Authorities do not wish these filled.

\section{Alberta Hospital Ponoka}

J. B. WALSH

Ponoka, Alberta, Canada

\section{Job description - description of jobs}

\section{Dear Sirs}

There has been much discussion about job descriptions. Is it time to look again at description of jobs? In the British Medical Journal of 20 May 1989, the following posts are advertised under psychiatry:

Consultant Psychiatrist

Consultant Mental Handicap

Consultant in Acute Mental Illness

Consultant in Psychological Medicine (Mental Handicap)

Consultant Psychiatrist (General Psychiatry)

Consultant in General Psychiatry

Consultant in Psychiatry (General)

Consultant in Psychogeriatrics

Consultant Psychiatrists (Psychogeriatrics)

Consultant Adolescent Psychiatrist

Consultant Psychiatrist in Adult Mental Illness

Consultant in Child and Adolescent Psychiatry

Consultant in General Adult Psychiatry

Consultant in the Psychiatry of Mental Handicap

Finally, one Authority is looking for "Locum Doctors in Psychiatry".

Would it not be a helpful convention that, at consultant level, all posts were described as "Consultant Psychiatrist in ...", the appropriate sub-speciality, as defined by the College Sections?

St Richard's Hospital

K. A. O'KeEFFE

Chichester PO19 4SE 